\title{
Ley natural, determinatio y derecho positivo Lo indiferente y las determinaciones del legislador
}

\author{
SEBASTIÁN CONTRERAS AgUIRRE \\ Universidad de los Andes (Chile) \\ scontreras2@miuandes.cl
}

\begin{abstract}
Resumen
Uno de los tópicos principales de la teoría clásica del derecho natural es el de la relación entre derecho natural y positivo. Para todos los autores clásicos, el derecho positivo encuentra su origen en los principios universales del derecho, que Santo Tomás ha llamado lex naturalis. Pero estos principios universales del derecho son tan generales e inespecíficos, que para formar parte de un ordenamiento jurídico concreto (en una comunidad política concreta) necesitan de alguna especificación. Este modo de «especificar» los preceptos naturales de moralidad es lo que se llama determinación, que es el tema de nuestro trabajo.
\end{abstract}

Palabras clave: determinación, ley natural, ley positiva, Aquino.

\section{Natural law, determinatio and positive law The indifferent and the determinations of the legislator}

\begin{abstract}
One of the main topics of classical iusnaturalism is the relation between natural law and positive law. For all the classics, positive law originates from the universal principles of law, that Aquinas calls lex naturalis. But these universal principles of law are so general and nonspecific, that to be part of a particular justice system (in a particular political community) needs some specification. This form of «specify» the natural precepts of morality is called determination, that is the topic of our work.
\end{abstract}

Key words: determination, natural law, positive law, Aquinas.

El autor es Magíster (C) en Filosofía por la Universidad de los Andes y Becario Conicyt para estudios de Doctorado en Filosofía en la Pontificia Universidad Católica de Chile. Actualmente se desempeña como profesor de Filosofía del Derecho en la Pontificia Universidad Católica de Chile y de Derecho Natural en la Universidad de los Andes.

El presente trabajo se ha desarrollado en el marco del Proyecto FONDECYT $N^{\circ}$ 11090189. 


\section{Planteamiento}

El presente trabajo busca desarrollar el problema de la determinación del derecho positivo. Santo Tomás la entiende como uno de los modos de derivación de la ley humana desde la ley natural, y, particularmente, como el modo de derivarse la ley humana que da origen a las normas de derecho positivo (o de derecho civil). Estas normas no son, en su naturaleza, simples conclusiones necesarias y más o menos directas de lo justo natural; son, al contrario, el resultado de elecciones libres del legislador, y de aquello que la ley natural había dispuesto solamente de manera general e inespecífica.

Dado esto, en las páginas que siguen hemos intentado mostrar al lector la naturaleza de la derivación por vía de determinación, según el modelo del iusnaturalismo de Santo Tomás, y teniendo presente dos ideas básicas, a saber: i) en la derivación por vía de determinación, el legislador está obligado a sujetar su actividad constructiva de la norma jurídica tanto a los principios generales de la razón natural como a las circunstancias particulares de su comunidad política; ii) las determinaciones pueden ser de dos tipos: unas puramente completivas o concretizadoras, y otras específicamente constructivas.

\section{Naturaleza de la determinatio}

Pese a que la ley natural se encuentra perfectamente adecuada a la naturaleza del hombre, no se halla, sin embargo, completamente conformada a la condición del hombre que vive aquí y ahora ${ }^{1}$. Por eso necesita ser determinada por lo justo legal o positivo, porque la ley natural, dice Kluxen, se refiere tan sólo a los contornos de la acción, no a sus particularidades ${ }^{2}$.

Lo justo legal es, de esta manera, un ordenamiento de la razón que especifica aquello que está indeterminado por lo justo natural (pero que concuerda con éste); que está orientado o dirigido hacia el bienestar de una comunidad política particular, y que «solo surge una vez que el legislador ha llevado a cabo una actividad intelectual consistente en medir la realidad con el fin de establecer una norma o regla capaz de

\footnotetext{
1 R. PIZZorni: La filosofía del diritto secondo Tomasso d'Aquino. Studio Domenicano, Bologna 20034, 619.

2 W. KLuXen: L'etica filosofica di Tommaso d'Aquino. Vita e Pensiero, Milano 2005, 333.
} 
dirigirla» ${ }^{3}$. Así, este derecho legal o positivo, es el resultado de las determinaciones autoritativas del legislador, que consisten, esencialmente, en elecciones entre distintas posibilidades igualmente razonables para el cumplimiento de lo justo natural aquí y ahora; esto porque, escribe Rodríguez Luño, «muchos de los principios éticos de justicia admiten diversos modos de realización en la práctica» ${ }^{4}$.

En consecuencia, es por su carácter indeterminado que lo justo por naturaleza exige una concreción positiva que lo inserte dentro de la comunidad política como derecho vigente. Se explica, de esta forma, que la intervención legislativa de la autoridad civil no sea algo puramente facultativo; tal oficio concretizador de lo justo natural es para la autoridad política una tarea irrenunciable, y a tal punto, que «un estado que no procediera (...) a esta concreción, atentaría contra la ley natural $»^{5}$, precisamente porque la ley natural manda (aunque inespecíficamente) el bienestar político de la comunidad en tales condiciones de lugar y tiempo.

Esta tarea concretizadora de la ley natural no es la única de las funciones que pertenecen a lo justo positivo o civil. Junto con ésta, la ley positiva puede también mandar o prohibir aquellas cosas que no prohíbe la ley natural o la divina ${ }^{6}$; pero, por sobre todo, puede adicionar prescripciones a la justicia natural en todo aquello que se encuentre regulado por ésta tan sólo de una manera confusa e indeterminada. Por eso la ley positiva no es una mera prolongación de la ley natural en la vida política; si así lo fuera, no veríamos en el legislador actos de autoridad creadores del derecho como lo son estas determinationes?

Pues bien, las formas de determinación van desde la elección de la fórmula lingüística más apropiada para expresar los requerimientos de la justicia natural, «hasta los agregados de tiempo, modo, sujetos, lugares, relaciones etc., que son necesarios para que esa exigencia natural pase a ser un elemento operante en la vida jurídica» ${ }^{8}$. En este sentido, de lo que se trata en la determinatio, es de ir más allá de las regulaciones imperfectas

J. GARCíA-Huidobro: “Averroes y el derecho natural. Análisis de su comentario a un texto aristotélico", ponencia en la primera sesión de las conferencias bimensuales de la Sociedad Chilena de Filosofía, marzo de 2011 (texto no editado).

4 A. Rodríguez LuÑo: Ética general. Eunsa, Pamplona 20065 263.

5 M. RHONHEIMER: Ley natural y razón práctica. Una visión tomista de la autonomía moral. Eunsa, Pamplona 2000, 466.

6 Marcos De Santa Teresa: Compendium Moralis Salmanticense, III, 4, 6.

7 Cfr. G. RoBles: Introducción a la teoría del derecho. Debate, Madrid $2003^{6}, 87$.

8 J. GARCÍA-HuIDOBRO: Razón práctica y derecho natural. Edeval, Valparaíso 1993, 179. 
de lo justo natural ${ }^{9}$ (imperfectas no metafísica, sino operativamente), que no formulan el contenido objetivo de cada acción concreta ${ }^{10}$, sino que ordenan nuestras acciones únicamente de manera general e inespecífica.

Estas determinaciones del legislador quedan comprendidas en normas de derecho civil o positivo. Tales normas no son, en su naturaleza, simples conclusiones necesarias y más o menos directas de lo justo natural; son, al contrario, el resultado de elecciones arbitrarias aunque aprovechables para alcanzar la vida virtuosa en esta comunidad ${ }^{11}$, y de aquello que la ley natural había dispuesto solamente de manera confusa e incoativa. Un ejemplo de esto, observa Fray Luis de León, lo vemos a propósito de las normas que ordenan el culto a Dios. Porque, si bien la ley natural ordena que demos culto y veneremos a Dios con sacrificios, «y que con cierto honor y culto nos entreguemos a Él [...], no determina de qué modo o mediante qué ofrendas hay que hacerlo» ${ }^{12}$. Así, a fin de precisarlas y establecerlas pormenorizadamente, fue necesaria la ley humana, puesto que, de lo contrario, no sería posible salir de la generalidad e indeterminación de los preceptos naturales.

Ahora, lo «arbitrario» de las normas civiles o positivas, debe entenderse únicamente en un sentido filosófico. Según esto, se llaman «arbitrarias» sólo en cuanto son normas que pueden existir o no existir, o que pueden existir de diversa manera; por ejemplo, «es posible que no haya ley alguna que prescriba solemnidades para los contratos, y es posible también que dichas solemnidades fueran distintas de las que se hallan preceptuadas. De aquí, empero, no se sigue que al legislador le sea dado obrar caprichosamente: el uso que haga de su autoridad debe ser siempre ajustado a la razón y encaminado al bien común» ${ }^{13}$.

Supuesto este sentido de «arbitrarias», debe advertirse, no obstante, que en el vasto campo donde la autoridad política, más que aplicar o ratificar determinados principios o reglas de la razón natural, construye determinaciones, «hay relativamente pocos puntos en los que su elección pueda ser razonablemente considerada como sin trabas o arbitraria ${ }^{14}$. Esto porque en la vida social no se dan alternativas que sean igualmente satisfactorias o insatisfactorias en todos sus aspectos, de manera que respecto de ellas pudiera darse una elección realmente arbitraria. Por este

9 M. ADLER: "Una cuestión acerca de la ley", en R. Brennan (ed.), Ensayos sobre el Tomismo. Ediciones Morata, Madrid 1962, 274.

10 Cfr. M. RHONHEIMER: Ley natural y razón práctica, $466 \mathrm{ss}$.

11 Cfr. Fray Luis De LEÓn: De Legibus, q. 6, a. 2.

12 Fray Luis DE LEÓN: De Legibus, q. 6, a. 1.

13 R. FERNÁNDEZ CONCHA: Filosofía del derecho o derecho natural. Tipografía Católica, Barcelona 1887, 173.

14 J. FINNIS: Ley naturaly derechos naturales. Abeledo-Perrot, Buenos Aires 2000, 313. 
motivo, la elección legislativa entre «conducir por la izquierda» o «conducir por la derecha», por ejemplo, es una cuestión indiferente tan sólo en abstracto, pero no lo es en una sociedad donde en virtud de un acuerdo o convención informal, «la gente ya tiende a conducir por la izquierda, y ha adaptado de modo consecuente sus hábitos, la construcción de sus vehículos, el diseño de los caminos y los objetos en las calles» ${ }^{15}$.

Volviendo al problema de la naturaleza de las determinaciones, observa Santo Tomás que los preceptos de la ley natural son de tal manera generales, que por eso necesitan de alguna especificación. Y así, por ejemplo, «es una exigencia clara de la razón natural que en una gran comunidad haya funcionarios, jueces y soldados; que haya un determinado orden y procedimiento penal; que para ciertos delitos haya también determinadas penas. Igualmente es necesario que los miembros de la sociedad colaboren a la conservación del todo mediante contribuciones, impuestos, prestaciones personales, etc. Pero lo que en cada caso es necesario, según las exigencias del momento, cómo y cuándo y dónde y por quién han de ser prestadas, no está determinado por la ley moral natural, sino que es misión del poder público

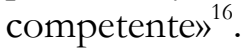

De acuerdo a lo anterior, el rasgo característico de la determinatio es su condición de no necesaria. Es decir, lo de opcional o elegible que hay tras la actividad inventiva del legislador. Esto quiere decir que en la puesta en práctica de la prudencia de la autoridad «interviene un factor de elección entre distintas posibilidades», entre las cuales, incluso, podrían hallarse alternativas contrapuestas. Porque, insiste Hervada, «si una regla fuese la única posible y derivase necesariamente (...) de un precepto natural, ya no sería ley positiva, sino un precepto de ley natural, porque ello indicaría que su origen estaría en la naturaleza humana y no en la voluntad del hombre» ${ }^{17}$.

Todo lo dicho puede entenderse claramente con el siguiente ejemplo. «Si los bienes materiales han de ser usados eficientemente para el bienestar humano, normalmente debe haber un régimen de propiedad privada. Este régimen estará constituido por reglas que asignen derechos de propiedad sobre tales bienes, o sobre muchos de ellos, a individuos o grupos pequeños. Pero precisamente qué reglas deberían establecerse con el fin de constituir un régimen así es algo no resuelto (...) por esta

\footnotetext{
15 Ibíd., 314.

16 V. Cathrein: Filosofía del derecho. El derecho natural y el positivo. Reus, Madrid 1958, 200.

17 J. HervadA: Introducción crítica al derecho natural. Eunsa, Pamplona 19989 167.
} 
exigencia general de justicia», de modo que la elección razonable de tales reglas «está en alguna medida guiada por las circunstancias de una sociedad particular, y en alguna medida es arbitraria» ${ }^{18}$.

Ahora bien, como límite de su actividad inventiva, debe el legislador sujetarse a lo dispuesto por la ley de la naturaleza. La razón de ello, es ésta la causa ejemplar de la ley humana, la mejor y la más verdadera de todas las leyes que existen ${ }^{19}$ (esto se entiende, naturalmente, en el contexto de la tradición escolástica). De esta forma, la libertad creativa de la autoridad se manifiesta, fundamentalmente, en su incapacidad para obligar y constreñir sin el sostén de un mandato genérico de la naturaleza ${ }^{20}$, lo que se traduce en que su capacidad inventiva no es completa, sino que más bien consiste en una libertad afectada.

Por este motivo, ha insistido Finnis que para ser en sí misma autoritativa a los ojos de un hombre razonable, una determinatio debe ser coherente con las exigencias básicas de la razonabilidad práctica, aunque no tiene por qué ser necesariamente, ni siquiera usualmente, la determinatio que él mismo habría hecho si hubiera tenido la oportunidad de legislar. De ahí que «el acto de poner el derecho (sea judicial o legislativamente o de cualquier otra forma) sea un acto que puede y debe ser guiado por reglas y principios morales ${ }^{21}$, a saber, los principios y reglas de la justicia natural. Éstos son, como escribe Ollero, el primer elemento jurídico «que late en el orden universal, aunque no sean todavía realidad jurídica, cosa justa, sino solamente principios orientadores de su búsqueda» ${ }^{22}$.

En consecuencia, no sólo las concretizaciones de lo justo natural, sino que también las especificaciones constructivas de lo justo político aquí y ahora por parte del legislador, deben sujetarse a lo dispuesto por la ley de la naturaleza. En este sentido, la autoridad política ha de incorporar en sus determinaciones la justicia de la ley natural, para así aplicarla a las concretas relaciones de la convivencia social y política ${ }^{23}$ (precisamente de esta sujeción de lo justo positivo a lo justo natural les viene a las determinaciones su fuerza obligatoria). Dado esto, cuando el legislador regula una materia indiferente a la ley natural y la impone a los ciudadanos, no realiza una constitución radical de su racionalidad o

18 J. FINNIS: Ley natural y derechos naturales, 312-313.

19 FRAY LUIS DE LEÓN: De Legibus, q. 1, a. 4.

20 G. GRANERIS: La filosofía del derecho a través de su historia y de sus problemas. Editorial Jurídica de Chile, Santiago 1979, 74.

21 J. FINNIS: Ley natural y derechos naturales, 316.

22 A. OlLERO: Interpretación del derecho y positivismo legalista. Edersa, Madrid 1982, 45.

23 Cfr. A. FERnÁNDEZ-GALIANO: Derecho natural. Introducción filosófica al derecho. Ceura, Madrid 19823, 133. 
bondad, sino solamente una definición de su carácter vinculante y normativo. Entonces, únicamente puede imponerse jurídicamente un objeto o materia que ya pertenezca a la racionalidad humana, aunque sólo se halle incoativamente regulado por lo justo natural. «Éste es el sentido, ciertamente restringido, de la expresión: es justo porque lo impone el legislador» ${ }^{24}$.

Por último, lo fundamental de la determinatio está, nos parece, no tanto en la función de complemento y aplicación que tiene lo justo positivo con respecto a lo justo natural, sino en la capacidad que tienen las normas positivas para hacer mutar lo que es justo por naturaleza (lo que por ley natural se mantiene indiferente o indeterminado). Por esta razón, «que la adición de reglas de la ley positiva puede suponer algún cambio en la ley natural es un hecho de experiencia» ${ }^{25}$, e incluso algo exigido por la misma condición indeterminada de lo justo natural.

Tal adición puede verse en el caso de un contrato. Así, mientras que por naturaleza bastaría la pura capacidad de las partes para que dicho acto de contratar se reputara perfecto, por las determinaciones de la autoridad, lo justo positivo podría añadir a la mera declaración de voluntades una serie de formalidades o condiciones de validez más allá de las que por naturaleza serían exigidas para que dicho negocio fuera considerado como jurídicamente existente ${ }^{26}$.

De esta manera, y tal y como ocurre en la realización de un artefacto, el cual no existe formalmente mientras no se halle plenamente concretizado (determinado) ${ }^{27}$, así también no existe el hecho jurídico, por ejemplo contrato de donación, si es que los contratantes no han ajustado sus conductas a las determinaciones de la autoridad. Porque, insiste Santo Tomás, una vez que el legislador ha completado los requerimientos indeterminados de la justicia natural, entonces ya no es indiferente que esto sea de tal o cual modo; al contrario, hacer eso es justo y omitirlo es injusto ${ }^{28}$.

Dado lo expuesto, en este proceso de la determinatio existe una verdadera creación del derecho por parte de la autoridad, precisamente porque la norma positiva resultante no sólo concretiza, sino que «completa, mediante factores positivos, el orden natural, que sin este complemento no regularía plenamente las relaciones sociales a causa de su indeterminación». Y así, por ejemplo, «existe el derecho natural al

24 J. Castillo: El pensamiento jurídico-politico de Fray Luis de León en el Tratado De Legibus. Universidad de Burgos (tesis doctoral), Burgos 1998, 396.

25 J. Hervada: Historia de la ciencia del derecho natural. Eunsa, Pamplona 199633 169.

26 FERNÁNDEZ CONCHA: Filosofía del derecho o derecho natural, 173.

27 J. FINNIS: Ley natural y derechos naturales, 311.

28 SANTO TOMÁs DE AQUINO: In Ethicorum, V, lect. 12, n. 1020. 
trabajo, pero este derecho no es ejercible dentro del sistema jurídico (...) si no es a través de su concreción en relaciones jurídicas individualizadas por medios de derecho positivo: contratos, convenios colectivos, legislación» ${ }^{29}$.

Finalmente, más allá de la pura función completiva que tiene lo justo positivo con respecto a los requerimientos de la justicia natural, lo que importa, realmente, en la doctrina de la determinatio, es el hecho de que la propia ley humana, en tanto que causa o razón del derecho, crea ciertos contenidos de justicia que, una vez regulados, deben ser respetados por todos (como si fueran mandados por la justicia natural). Nada de esto revierte el carácter de causa ejemplar que lo justo natural tiene respecto de la ley humana, porque, como ha apuntado Waldstein, la ley natural, en tanto que está inscrita en el corazón del hombre, es siempre un punto de referencia normativo para lo justo civil $^{30}$.

\section{La determinatio en Santo Tomás \\ y la necesidad de concreción de lo justo por naturaleza}

El derecho natural de Santo Tomás no es un sistema normativo contrapuesto al derecho positivo o simplemente legal. Tampoco es un sistema, en estricto sentido, porque no consiste en un ordenamiento jurídico cerrado sobre sí al modo del derecho natural de Pufendorf, donde las reglas particulares de justicia deben deducirse axiomáticamente, more geometrico, desde los principios universales del derecho, conformando así un sistema rígido y clausurado sobre sí mismo.

El derecho natural de Santo Tomás es más bien una parte del único ordenamiento de justicia que es el derecho de la comunidad (o derecho político), donde además de las normas de justicia natural, «existen otras leyes que consideradas en sí mismas no hallan razón para su observancia», pero que una vez consideradas todas las circunstancias particulares de esa comunidad "se hace conveniente que sean

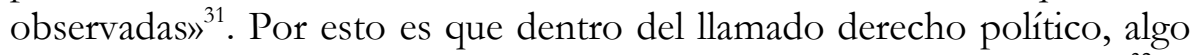
es justo o por naturaleza o porque la ley humana así lo ha instituido ${ }^{32}$, y

\footnotetext{
29 HERVADA: Introducción critica al derecho natural, 179.

30 Cfr. W. WALDSTEIN: "Derecho positivo y ley natural", Nuntium, n 9 (2003), 33.

31 SANTO TOMÁs: In Sententiarum, III, d. 3, a. 3.

32 Cfr. SANTO TOMÁs: In Ethicorum, V, lect. 12, n. 1017.
} 
en tal caso los dictámenes del legislador valen tan sólo para los que están sujetos a la jurisdicción de esa ciudad o de ese gobernante ${ }^{33}$.

Ahora bien, advierte Santo Tomás que lo justo natural, sea derecho natural primario, sea derecho de gentes, es insuficiente para la regulación de la vida moral y política. Es preciso, de esta manera, que la razón práctica llegue a soluciones más concretas partiendo de las exigencias indeterminadas de la ley natural. Es esto lo que explica la necesidad de este proceso constructivo de las normas positivas que se ha denominado simple determinación o concretización, y en virtud del cual lo que la autoridad decide, «dejando a salvo el derecho natural, se convertirá en justo y adquirirá valor ético» ${ }^{34}$.

Esta necesidad de unas especificaciones de lo justo por naturaleza se encuentra ya presente en la obra de San Alberto. Probablemente por eso el Aquinate haya insistido más en la función concretizadora que en la función creativa de lo justo civil o positivo, que, no obstante encontrarse potencialmente contenido en el derecho natural, no es de ninguna manera un derecho natural. Esto porque los preceptos de derecho civil no son más que determinaciones remotas y particulares de lo justo por naturaleza, que se ocupan no de lo universal y necesario, sino de la diversidad de circunstancias en las que se desarrollan los actos humanos $^{35}$. Se explica, por ende, que se trate de un derecho puesto y causado por el hombre, aunque enraizado en la ley natural. De ahí que Santo Tomás, lo mismo que Cicerón, escriba que lo justo legal o positivo tiene siempre su origen en el derecho natural ${ }^{36}$.

Observa Santo Tomás que junto a los preceptos de derecho natural, hay otros preceptos que no toman su fuerza obligatoria de la razón natural, "porque esos preceptos no implican un concepto absoluto de cosa debida o indebida $\aleph^{37}$. Antes bien, su fuerza obligatoria les viene no directamente de lo justo por naturaleza, sino de la misma autoridad divina o humana que los determina como derecho vigente. Si estas determinaciones están hechas por institución divina en materias que miran a Dios, se llaman preceptos ceremoniales; si están hechas por institución divina, pero en cosas que miran a las relaciones de unos hombres con otros, se llaman preceptos judiciales ${ }^{38}$. Si, en cambio, están hechas por institución humana, y respecto de aquellas materias que dicen

\footnotetext{
33 Cfr. SAnto TOMÁs: In Ethicorum, V, lect. 12, n. 1021.

34 F. Olgiati: El concepto de juridicidad en Santo Tomás de Aquino. Eunsa, Pamplona 1977, 262.

35 SAN AlBerTo: De Bono, tract. 5, q. 1, a. 1.

36 SANTO TOMÁs: In Ethicorum, V, lect. 12, n. 1023.

37 SANTO TOMÁs: Summa Theologiae, I-II, q. 104, a. 1.

38 Cfr. SANTO TOMÁs: Summa Theologiae, I-II, q. 104, a. 1.
} 
relación directa con el logro del bienestar político de una comunidad particular, se llaman preceptos de derecho civil o de derecho positivo estricto. Es a éste al que hemos dedicado la mayor parte de este trabajo, porque la determinatio que se aplica a las normas de derecho civil parece ser el sentido focal de las determinationes en el pensamiento de Santo Tomás. Porque, de hecho, cuando el Aquinate trata de los preceptos ceremoniales y judiciales, da por supuesto todo lo indicado anteriormente a propósito del derecho civil o simplemente legal.

Entonces, junto a las normas que se derivan de los principios comunes de la ley natural por vía de conclusión, «hay otras normas que se derivan por vía de determinación; y así, la ley natural establece que el que peca sea castigado, pero que se le castigue con tal o cual pena es ya una determinación añadida a la ley natural» ${ }^{39}$. Y así, que los ladrones sean castigados es algo exigido por la justicia natural, pero la forma precisa de penalidad ha de ser puesta por la ley humana. Por esto concluye Santo Tomás que si bien es cierto que la ley natural dicta que la pena se debe aplicar en relación a la culpa, la determinación de la pena según las condiciones de la persona y la concreta magnitud de la culpa corresponde al derecho positivo ${ }^{40}$.

Lo anterior explica por qué la norma positiva o civil no dice «no se debe matar», sino que especifica los distintos tipos de homicidio sin detenerse en consideraciones acerca de la bondad o maldad del acto de matar (cuestión que ya está resuelta por la justicia natural). Luego, más que obtenerse como una deducción desde lo justo natural, lo justo positivo «contiene los preceptos naturales» ${ }^{41}$, tal y como toda proposición especulativa verdadera contiene de algún modo los primeros principios del pensamiento teorético.

Dado lo expuesto, una vez llevada a cabo la determinación, la norma resultante no es ya un derecho natural puro ni tampoco una norma natural positivada (que sería el derecho de gentes), sino sólo lo justo instituido «arbitrariamente», un conjunto de normas-complemento que surgen a partir de la libre inventiva del legislador humano ${ }^{42}$, aunque dentro de los márgenes de la delegación normativa que ha recibido éste para el ejercicio de sus funciones. Tales normas no reciben, al menos no directamente, su fuerza obligatoria desde los primeros principios del

\footnotetext{
39 SANTO TOMÁs: Summa Theologiae, I-II, q. 95, a. 2.

40 SANTO TOMÁs: In Sententiarum, IV, d. 36, q. 1, a. 1.

41 J. MARTíneZ: Reconsideraciones sobre el pensamiento político de Santo Tomás de Aquino. Editorial de la Facultad de Filosofía y Letras de la Universidad Nacional de Cuyo, Mendoza 1999, 208.

42 Cfr. D. Herrera: La noción de derecho en Villey y Kalinowski. Educa, Buenos Aires $2005,210$.
} 
orden práctico, «sino sólo de su autor, el legislador positivo, que (...) goza de una delegación y ejerce un poder real aunque limitado. Crea, en el sentido fuerte de la palabra, nuevos preceptos, a condición de permanecer dentro de los límites de la delegación del poder legislativo, esto es, de no estatuir contra las exigencias de la ley natural» ${ }^{43}$, que son, de hecho, el único límite al ejercicio de su potestad (sin embargo, bien podría pensarse que también la delegación misma supone ya un límite al ejercicio de sus facultades).

En este sentido, la norma positiva no puede abrogar los mandatos y prohibiciones naturales; esto es, «no puede destruir la obligatoriedad de la norma jurídica natural que prescribe o prohíbe una conducta», porque tal obligatoriedad no es extrínseca a la norma de justicia natural, sino un elemento constitutivo suyo, en tanto que dicha obligatoriedad «se asienta en un deber de justicia fundado en la naturaleza humana» ${ }^{44}$. Por esta razón, una norma positiva verdadera no podrá estar en conflicto con la norma natural, aunque sí podrá, por ejemplo, disponer la limitación de algunos derechos en razón de la felicidad común, como cuando se suspenden derechos individuales que, por la misma razón natural en que se fundan, están subordinados a ese bien común.

Así, y por razones de necesidad pública, puede limitarse el uso de ciertos bienes, o el ejercicio de ciertas libertades. Esto no supone una oposición entre lo justo legal y lo justo natural, precisamente porque es de derecho natural el cumplimiento de las determinaciones de la autoridad y el logro de este bien común en estas circunstancias de tiempo y lugar (donde tales determinaciones son las más adecuadas). En estos casos, y otros semejantes, sea tolerando actos de suyo malos, sea exigiendo determinadas pruebas para reconocer las obligaciones, sea sujetando a solemnidades la validez de los actos jurídicos, sea limitando en materias de su competencia la libertad o el dominio individual, con tal que obre con razón proporcionada y por el bien común, la ley positiva no atenta contra la natural ${ }^{45}$. Y esto porque es su tarea especificarla y darle una aplicación prudencial en estas circunstancias particulares.

Por lo tanto, además de ser aplicable cuando de hecho se conforma con lo justo natural, el derecho positivo es también aplicable cuando es indiferente ante el derecho natural el que una cosa sea hecha de uno u otro modo, o incluso cuando el legislador, por la consideración de unas muy particulares circunstancias, decide la restricción de ciertos derechos

43 G. KalinowsKi: Concepto, fundamento y concreción del derecho. Abeledo-Perrot, Buenos Aires 1982, 69.

44 HERVADA: Introducción crítica al derecho natural, 173.

45 Cfr. FERNÁNDEZ CONCHA: Filosofía del derecho o derecho natural, 171. 
en razón de la felicidad común. Ahora, independientemente de cuál sea el caso, lo que importa en cuanto a las determinaciones, es que una vez que la ley ha sido establecida, aquello que decide la autoridad deja de ser indiferente, porque entonces «observar esto es justo, y desecharlo es injusto» ${ }^{46}$. "Por esto dice el Filósofo (...) que lo justo legal es lo que, en principio, nada exige que sea así o de otro modo; mas una vez establecido, si debe ser de un modo y no de otro». Sin perjuicio de ello, si algo connota una oposición efectiva con la ley natural, «no puede hacerse justo por la voluntad de los hombres, como si se estableciera que es lícito robar o adulterar. Y por eso exclama Isaías: iAy de aquellos que redactan leyes inicuas: ${ }^{47}$.

Con todo, Santo Tomás explica la naturaleza de la determinación apelando solamente al caso de la especificación de las penas y a la analogía entre la tarea del legislador y la actividad del artesano. Si bien esto es insuficiente, no obstante ello parece interesante, piensa GarcíaHuidobro $^{48}$, porque, en efecto, no existe una única manera de diseñar una casa. Muchos diseños diferentes son sin ninguna duda bastante razonables. $\mathrm{Y}$ es más, mientras que ciertas características del proyecto serán determinadas por las necesidades de la persona o la familia que ocupará la vivienda, otras serán simplemente materia de estilo y gustos ${ }^{49}$.

Si esta analogía entre el proceder de la autoridad y la actividad del artesano es cierta, este mismo ámbito de libertad creativa que posee el artista ha de darse también en el surgimiento del derecho positivo o civil. Es esto lo que hace decir a George que, «al igual que el arquitecto, el legislador dispondrá en muchos ámbitos de su ejercicio de una considerable medida de libertad creativa [...] por medio de la cual creará diestramente planes concretos de regulación que apunten a la coordinación de la conducta en miras del bienestar general de la comunidad, es decir, del bien común $»^{50}$. Esto porque, al igual que en las

46 SANTO TOMÁs: In Ethicorum, V, lect. 12, n. 1020.

47 SAnto Tomás: Summa Theologiae, II-II, q. 57, a. 2. Según esto, observa Santo Tomás que «antes que se instituyeran las leyes, en nada difería hacer esto o aquello. Pero una vez instituidas (...) las cosas cambiaron, porque desde entonces lo justo va a consistir en observarlas y lo injusto en pasarlas por alto, como en cierta ciudad fue instituido que el cautivo sea redimido pagando un cierto precio, y que se sacrificara una cabra pero no dos ovejas».

48 Cfr. J. García-Huidobro: "La recepción de la doctrina aristotélica sobre el derecho natural en el Comentario de la Ética a Nicómaco de Santo Tomás de Aquino", Anuario Filosófico, vol. 32, n 1 (1999), 238-239.

49 Cfr. R. P. George: Entre el Derecho y la Moral. Aranzadi-Thomson, Navarra 2009, 51-52.

50 R. P. GeOrGe: "Natural law", Harvard Journal of Law \& Public Policy, vol. 31, n 1 (2008), 189. 
artes, donde la idea común tan sólo orienta la actividad del artesano sin especificarla en los detalles, la norma positiva está controlada pero no completamente determinada por lo justo natural ${ }^{51}$.

Todo esto nos permite afirmar que Santo Tomás está lejos de menospreciar el papel constructor de la prudencia legislativa, precisamente porque el ordenamiento de justicia emanado de las determinaciones de la autoridad no es una inventio, o hallazgo, sino una adinventio, un aedificatum, una constructio, en el sentido fuerte de los términos $^{52}$. Es por esto que el ordenamiento de justicia emanado de las determinaciones del legislador no es puramente contemplado, dice Lachance, sino verdaderamente construido por la autoridad.

En definitiva, las materias sobre las que recae la determinatio no son sino aquellas que de suyo no requieren una decisión en algún sentido determinado, sino simplemente una decisión que excluya otras posibles ${ }^{53}$. Por eso la determinatio se explica a partir del ámbito de lo indiferente, lo que no significa que la tarea creativa del legislador entrañe el ejercicio de una libertad absoluta. Esto significa, más bien, que la actividad inventiva de la autoridad es libre, pero dentro de los márgenes de la razonabilidad práctica, y sin que ello contravenga lo dispuesto por la justicia natural. De esta manera, escribe el Angélico, las normas positivas prohíben únicamente «lo que puede ser ocasión de males, o prescriben algo que ordena hacia la virtud $\rangle^{54}$.

Se sigue de todo lo expuesto que para Santo Tomás existe tanto un aspecto formal como un aspecto material de la justicia de estas determinaciones. Y mientras que su aspecto formal dice relación con su grado de conformidad o disconformidad con los «principios del derecho que se encuentran en la razón natural», que no cambian, en relación con su aspecto material propone el Aquinate que «lo justo y lo bueno no es lo mismo en todos los sitios y para todos, sino que corresponde a la ley su determinación. Esto sucede por la mutabilidad de la naturaleza humana y de las diversas condiciones de los hombres y de las cosas, según la diversidad de lugares y tiempos». Y por ejemplo, «siempre es justo que en una compra y venta se haga la transacción según lo equivalente; pero para medir el grano es justo que en cierto lugar o tiempo se dé una

51 Cfr. FINNIS: Ley natural y derechos naturales, 311.

52 Cfr. L. LACHANCE: Humanismo politico. Individuo y Estado en Tomás de Aquino. Eunsa, Pamplona 2001, 323.

53 J. T. Alvarado: La determinación del derecho en Santo Tomás. Pontificia Universidad Católica de Chile (tesis de licenciatura), Santiago 1993, 14.

54 SANTO TOMÁs: In Sententiarum, IV, d. 15, q. 3, a. 1. 
cantidad, y en otro lugar o tiempo no se dé ese tanto sino más o menos» ${ }^{55}$.

\section{Conclusiones}

Una vez que hemos abordado el problema de la naturaleza de las determinationes, lo primero que quisiéramos poner de relieve es la cuestión de la necesidad (y no sólo utilidad) de las leyes positivas. Éstas surgen, como se ha dicho, porque la ley natural no alcanza a regular cada uno de los aspectos de la vida social; por eso han de añadirse, ex humana industria, otras normas que completen lo justo por naturaleza y que puedan aplicarse directamente a nuestras acciones.

Estas determinaciones del legislador no son caprichosas e infundadas, aunque sí son «arbitrarias» como se ha dicho. Y no son caprichosas, porque la autoridad debe, en su función creadora del derecho, sujetarse tanto a los dictámenes de la recta razón como a las circunstancias particulares de lugar y tiempo en las que se ha propuesto su tarea de construcción de las normas positivas.

Ambos requisitos son copulativos. El legislador no puede especificar los preceptos naturales sin consideración de las circunstancias particulares de su comunidad. Es más: si sus determinaciones fueran únicamente un desarrollo «abstracto» de lo justo natural, entonces no habría diferencia alguna entre la determinatio y la derivación por vía de conclusión, que Santo Tomás postula para el surgimiento de las normas del derecho de gentes. El legislador tampoco puede sólo considerar las circunstancias particulares de su comunidad, con prescindencia de los principios de la razón natural. En este caso, escribe Santo Tomás, sus determinaciones no serían más que corrupciones de la ley.

También debe ponerse de relieve el carácter obligatorio de las determinaciones. El propio derecho natural exige que los hombres se sometan a sus legisladores. Así lo han entendido los escolásticos, para quienes siempre hemos de cumplir las prescripciones de la autoridad, a pesar de que éstas no revistan un carácter necesario per se como las normas del derecho natural.

Ahora bien, para la elaboración de sus determinaciones, que, como hemos visto, son esencialmente obligatorias, aunque variables $y$ contingentes (y es fundamental que sea asî), el legislador humano goza de una cierta libertad creativa. Santo Tomás piensa que esta libertad del legislador es tal, que, por ejemplo, la especificación de las penas queda

55 SANTO TOMÁs: De Malo, q. 2, a. 4. 
entregada a su entera discrecionalidad, siempre que el ejercicio de esa discrecionalidad no sea contrario a la recta razón. Dicha libertad inventiva del legislador se traduce en una potestad para hacer mutar lo que es justo por naturaleza, a partir de una serie de concreciones o construcciones autoritativas que sean indispensables para la consecución del bienestar social ${ }^{56}$.

En la particularización de estas determinaciones el legislador es completamente libre; las normas naturales operan solamente como principios de orientación de su búsqueda de lo justo en el caso concreto. Lo importante, sin embargo, es que estas determinaciones mantengan, al menos mediatamente, una vinculación racional con los principios generales de la moralidad ${ }^{57}$. Dado esto, lo propio de las leyes positivas no es ser meras explicitaciones de lo justo natural. Si así lo fueran, la ley humana sería radicalmente imperfecta, porque dejaría de atender los aspectos que hacen justamente posible la comprensión y el cumplimiento aquí y ahora de lo preceptuado por la recta razón ${ }^{58}$.

Por lo tanto, bien puede concluirse que a lo justo positivo se lo tiene por ley siempre que no hay ley ${ }^{59}$, esto es, siempre que se mantenga en el derecho un espacio de indeterminación. Esto se traduce en que las especificaciones de la autoridad vienen exigidas por el propio carácter incompleto de lo justo natural. Porque, a pesar de que se trata éste del sustrato originario de la justicia, es sin embargo insuficiente para ordenar la vida moral y política. Por ello debe ser concretado, determinado y desarrollado en función del bien común político de cada pueblo ${ }^{60}$.

En definitiva, el derecho natural «no pervive solitario en la idea, aislado del derecho positivo con el que evitaría todo contacto» ${ }^{61}$. Al contrario, está llamado a concretizarse y tomar una forma histórica determinada mediante su positivación ${ }^{62}$. Por esto es que no existe como un ordenamiento de justicia independiente del derecho natural, sino que como encarnado en las construcciones autoritativas del legislador ${ }^{63}$.

56 Cfr. R. P. GeORGE: "Derecho natural y derecho positivo", Persona y Derecho, no 39 (1998), 232.

57 Cfr. J. FINNIS: Aquinas. Moral, political and legal theory. Oxford University Press, Oxford 2004, 267.

58 Cfr. F. PuY: Lecciones de derecho natural. Introducción a la ciencia del derecho natural. Porto Editores, Santiago de Compostela 1970², 344.

59 Cfr. Á. RoDríguez LuÑo: Ética general, 198.

60 Cfr. Á. Rodríguez LuÑo: "Del derecho positivo a la justicia", Nuntium, no 9 (2003), 46.

61 A. MEssineO: "Il diritto naturale e la sua immutabilità e assolutezza", Cività Cattolica, n 83 (1932), 494.

62 Cfr. A. M. GONZÁLEZ: Claves de ley natural. Rialp, Madrid 2006, 157.

63 Cfr. RHONHEIMER: Ley naturaly razón práctica, 500. 
Precisamente en esto consiste el arte del buen gobierno, en posicionar como derecho vigente aquello que tan sólo de manera indeterminada regula nuestras acciones. En decidir libremente cuáles normas positivas son las más convenientes para el logro del bienestar social aquí y ahora. En darle una aplicación prudencial a los requerimientos universales de la justicia natural, que inclusive puede traducirse en la restricción de ciertas libertades por causa de la necesidad pública. Pero, por sobre todo, en desarrollar una capacidad constructiva y concretizadora de lo justo natural según unas muy particulares circunstancias de lugar y tiempo, dentro de los márgenes de la razonabilidad práctica, y sin que ello signifique una contravención a la ley natural. Porque, como ya afirmaran los latinos, el derecho positivo puede siempre alterar los derechos civiles, más nunca los derechos naturales.

Sumario: 1. Planteamiento; 2. Naturaleza de la determinatio; 3. La determinatio en Santo Tomás y la necesidad de concreción de lo justo por naturaleza; 4. Conclusiones. 